Melanie Rockenhaus

Scuola Normale Superiore, Pisa, Italy

\title{
Teaching writing for high-stakes exams using communicative language teaching methods
}

\section{Introduction}

Writing is part of most standardized exams, and a necessary part of any gate-keeping exam for university studies in English. Students must therefore learn to write, and write well, but they are often unenthusiastic about it, either because anxious and insecure due to past negative experiences or simply because they find writing less engaging and tiresome (Harmer 2004). Moreover, writing in the exam preparation classroom is necessarily focused on form and language precision. Students need to be informed about task formalities, trained to respond to the task types they will find on the specific exam they are preparing to sit and given a chance to practice the writing section(s) of the exam. These lessons can seem frustratingly limited in their scope, with both students and the teacher concerned exclusively with exam results. There may be few opportunities for students to interact among themselves, leading to a regrettable loss of class interaction and collaboration. In fact, students often report the exam preparation class to be helpful but tedious (Kim 2010). This can be frustrating for students and instructors alike.

The so-called 'communicative classroom', instead, aims to attain curriculum objectives through the use of activities such as information sharing and learning by doing, activities students often perceive as appealing, motivating and stimulating (Richards and Rodgers 2001, Savignon 2002). Moreover, Charge and Taylor (1997) remind us that one very common high-stakes exam, the IELTS (International English Language Testing System), sprang from the early CLT movements, indicating 
the essential, possible connection between high-stakes exams and communicative teaching. Furthermore, although communicative language teaching (CLT) methods are generally perceived as being linked to speaking, Savignon (2002) makes it clear that CLT can be used to teach reading and writing as well.

This paper reports on a research project aiming firstly to understand if instructors use communicative tasks while teaching writing for gate-keeping exams, and to what extent. The second part of the research aimed to demonstrate that the use of CLT methods while preparing students for the writing section of a standardized exam can enhance student satisfaction and motivation while training the learners to complete the writing portion of the exam successfully.

\section{Literature review}

A great deal has been written about CLT and its applications in the classroom. A broad overview is offered by Richards and Rodgers (2001), who dedicate an entire chapter to CLT in their section on teaching approaches, exploring CLT historically from both theoretical and practical viewpoints. In looking at the practical classroom application of CLT, they list various types of activities which in their opinion fit into the communicative approach, claiming that the "range of exercise types and activities compatible with a communicative approach is unlimited" (Richards and Rodgers 2001:165). In his section on applications of writing research, Hyland (2002) considers a writing course which relies on problem solving and role playing, two typical CLT activities, pointing out that by integrating writing into students' genuine communicative aims the course permits students to develop a sense of writing for the real world. Harmer (2004) advocates a classroom pedagogy which includes group project writing, collaborative writing and exchanging writing. He encourages this latter activity in particular for correcting writing completed as practice for external exams.

In addition to Harmer's (2004) reference to using CLT methods while teaching writing for exams, only two studies were found specifically focusing on the use of CLT while preparing students for standardized exams. Kim (2010) reflects on an experience observing two exam preparation classes where CLT activities were used, including meaningful practice, problem solving and role playing, then recounts the use of similar activities in personal exam preparation classes. In a section titled "Rationale for using CLT in test-preparation classes" Kim (2010: 41) lists three good reasons to use a CLT approach while preparing students for high-stakes exams: because students are more motivated and engage more with the language, because they thereby develop greater linguistic proficiency, and because, after all, it is feasible. Luxia (2007) instead, examines whether the writing task in a standardized college entrance exam in China had the positive washback on the pedagogical practices of English language teaching in Chinese schools it 
had been designed to promote. The researcher concludes that high-stakes tests in themselves are not likely to be a positive agent for change, as both teachers and students preferred to concentrate on the testing results to be obtained rather than the communicative intent of the test itself. This interesting study will be discussed again in Section 5 below.

Lastly, Nunan (1989:148) defines various communicative tasks which can be employed in the classroom, including meaningful practice, rehearsal, role play and problem solving; these categories were used during the observation phase of colleagues to identify communicative activities and distinguish them from other classroom tasks.

\section{Methodology}

This section looks at the methodology used for both parts of the study. It is divided into a description of the participants and timing and a description of the instruments and procedures used for data collection, and methods of analysis.

\subsection{Study participants and timing}

For the first part of the study, I observed two colleagues preparing mostly fourthyear Italian university students for two different standardized exams, the Test of English as a Foreign Language (TOEFL) and the First Certificate in English (FCE), for a total of ten classroom hours. The objective of these observations was to understand to what extent competent colleagues incorporated communicative activities in exam preparation classes. Classroom activities focused on writing were of particular interest and were logged accordingly, as will be explained below.

In the second part of the study, the objective was to reutilize these colleagues' CLT practices alongside additional communicative activities during the writing training portion of an IELTS preparation course and then assess student satisfaction. Participants in this portion of the study were 32 first-year Italian university students. Total classroom time was forty hours, with ten of these hours being dedicated to preparing the students for the writing section of the IELTS.

Both the instructors and the students signed consent letters prior to the beginning of the research, and anonymity was guaranteed throughout.

\subsection{Instruments, procedures and methods of analysis}

The observation chart in Appendix A was used for the first part of the study. One chart was completed for every hour of teaching, for a total of ten charts. Nunan's (1989) 
categories were used exclusively for identifying communicative activities and distinguishing them from other classroom events. At the end of the ten classroom hours' observation time, results were tallied to understand a) overall time spent on CLT activities and b) time spent in communicative activities while teaching towards the writing portion of the exam being taught. Both instructors also agreed to a brief, non-structured interview about their teaching, and these interview comments were recorded.

For the second part of the study, CLT methods were utilized during the writing training portion of an IELTS preparation course with 32 first-year Italian university students. In an exam preparation class of forty hours overall, total classroom time dedicated to preparing the students for the writing section of the exam was ten hours. The instructor goal for this research project was to dedicate at least $40 \%$ of these ten hours to communicative activities. Examples of communicative activities used include jigsaw dictation, where students take turns dictating to each other, peer and group editing, creation of exam writing tasks and text comparison and auctioning. In this latter activity, students were given an unfinished text and then had to bid on sentences they needed to complete it. They then had to negotiate with their group to organize the sentences into a coherent short essay.

At the end of this high-stakes exam preparation class, students were requested to respond to a short survey containing three questions. These questions aimed to measure to what extent students felt their writing, textual control and vocabulary knowledge had improved, and why. This survey can be found in Appendix B. These results were tallied quantitatively and student comments were recorded.

Results from this portion of the survey were also compared to results which had been obtained two years prior from a group of students similar in size, age and exam preparation type. The question types were the same with the exception of the final portion, the why question, added to the 2011 survey in order to broaden the measurement of student satisfaction.

The results from both portions of the research are reported in the next section.

\section{Results}

This section is divided into classroom observation results and classroom research project results.

\subsection{Classroom observation results}

Ten classroom hours (600 minutes) of exam preparation were observed, five each for FCE and TOEFL preparation. During these classes, the instructors covered all four language skills, that is, listening, reading, writing and speaking, 
to prepare students for these separate tasks on the exams. Activities deemed to be communicative based on the task classification suggested by Nunan (1989: 148) were logged according to the beginning and ending time and the exam task they were designed to prepare for. There was also space for comments about the mechanics of the communicative tasks used so they could be more easily recycled if desired. The classroom observation chart can be found in Appendix A.

The results show that over one third of all classroom time, specifically 216 minutes, was devoted to communicative activities. Of these communicative activities, about $21 \%$ (45 minutes) were dedicated to preparing students for writing tasks. Table 1, below, shows this information graphically.

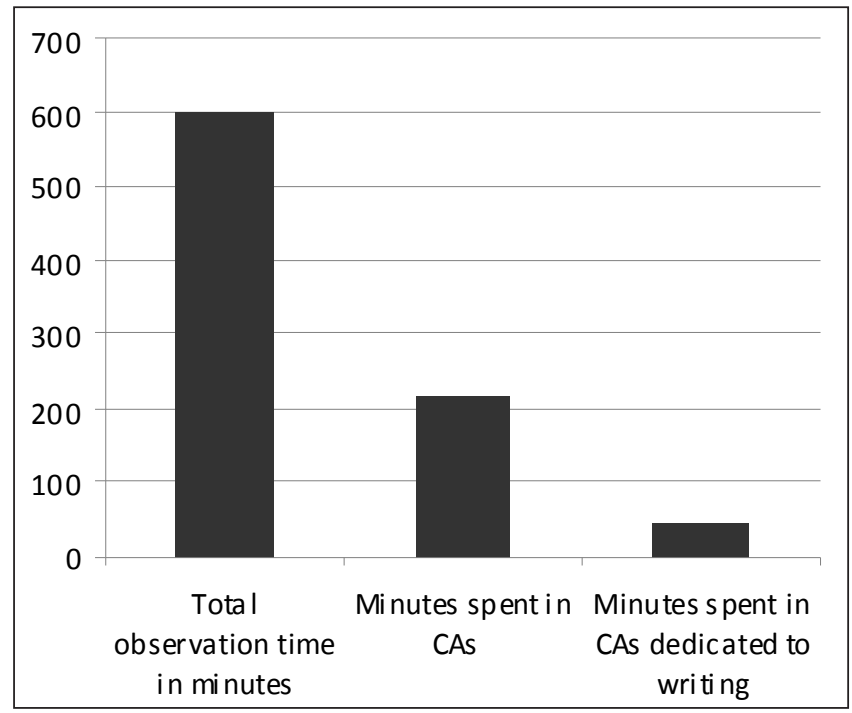

Figure 1. Time spent in communicative activities (CAs) in two exam-preparation classes

It should be noted that as neither of the instructors were aware of the exact purpose of the observations, interference of observer expectations on the classroom behavior of the teachers can be excluded. These encouraging results will be discussed in detail in Section 5 below.

The purpose of the observations was revealed to the instructors in the brief, unstructured interviews at the end of the observation periods, in order to better understand instructor choices as regards communicative activities while preparing for the writing task of each exam. The two instructors both commented that communicative activities for writing consumed more time in planning and seemed to require more time for classroom implementation than did activities for other exam tasks. For this reason the instructors tended to avoid using communicative activities while teaching writing for exams. These results will be commented on in Section 5 below. 


\subsection{Classroom research project results}

In the second part of the study, communicative activities were used during the writing portion of an IELTS preparation course with 32 first-year Italian university students. Ten hours overall were dedicated to preparing the learners for the writing section of the IELTS, and approximately four of these hours were dedicated to CLT activities. At the end of the course, student satisfaction was measured through a brief survey (Appendix B), where students were asked if their writing had improved, if they thought they had greater control over their writing, and if their vocabulary knowledge had improved. For all three of these questions, learners were also asked to reflect and comment about why they responded as they had. Results from this portion of the survey were also compared to results obtained two years prior from a group of students similar in size, age and exam preparation type, with the exception of the why questions, not listed on the 2009 survey.

In response to the question regarding writing improvement, 25/32 students said it had, as compared to 18/34 in 2009. 27 of the 32 students in 2011 felt they had more control over their writing after the course, as compared to only 20/34 in 2009. Vocabulary improvement was noticed by 22/32 students in 2011 as compared to only $21 / 34$ in 2009 . These results are presented graphically in Table 2 below.

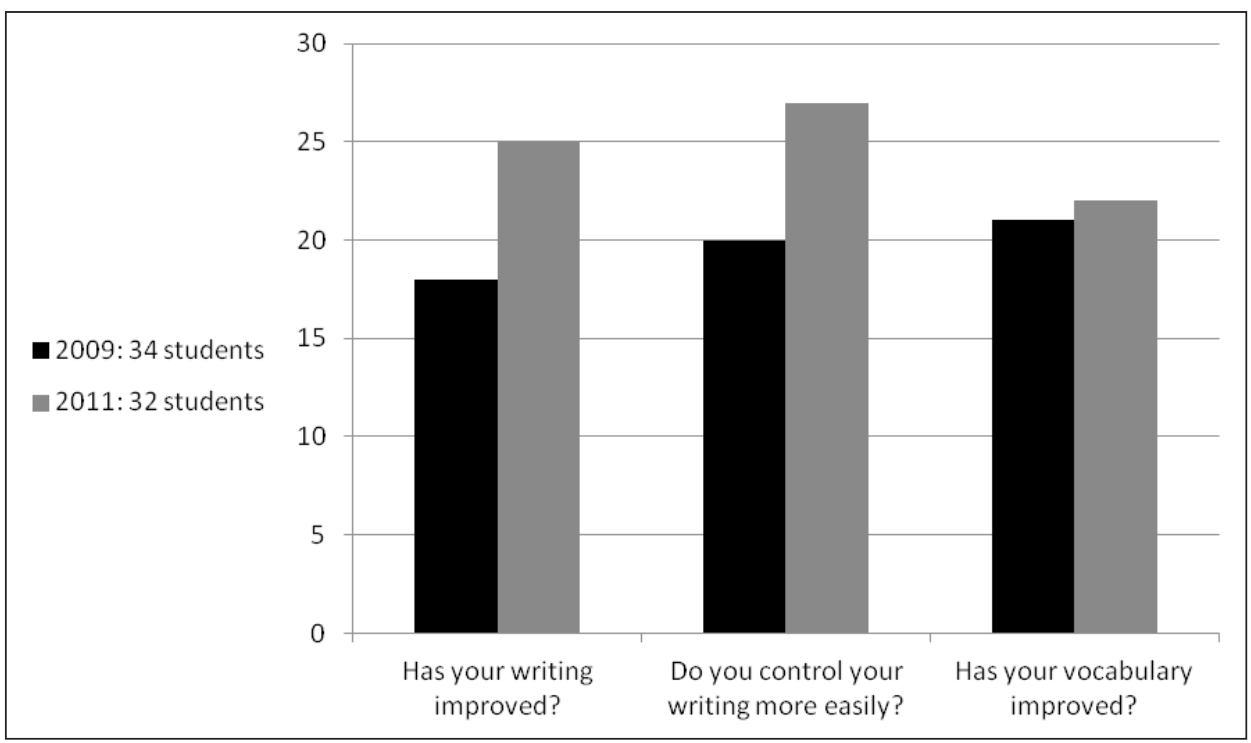

Figure 2. Comparison 2011 and 2009 student survey results

As can be seen from these results, satisfaction was greatly enhanced in the 2011 session, and student results on the actual IELTS exam was very good. No 
student scored less than 7.5/9 on the writing section. Unfortunately, IELTS results for the 2009 session are not available.

Student responses to the why portion of the survey were overall very positive as well, and point to the communicative nature of the teaching method. Three typical comments for each of these questions are listed below.

In response to the question, Has your writing improved? why? students commented: "I practiced a lot in class with my friends", "we wrote a lot and my friends helped me", "I learned not to be afraid of writing because most of the time we worked together".

For the question, Do you think you control your writing more easily? why? learners mentioned, for example, "my partner explained how he makes a paragraph", "I had to organize my ideas during group dictations", "I learned from my classmate that in English there's always an introduction and a conclusion".

Lastly, students responded to the question Has your vocabulary knowledge improved? why? by pointing out that "creating writing tasks with the others made me use a lot of words," I learned words while reading my friends' texts", "I didn't want to seem stupid when we worked together, so I prepared a lot".

As mentioned above, no such responses to why questions are available for the 2009 course. It should however be noted that there was a significant drop in negative comments overall. In the 2009 survey, despite the lack of solicitation about why students were satisfied or not, fully 10 students (nearly $1 / 3$ of the 34-member cohort) mentioned problems like the dullness of the IELTS tasks, the difficulty of concentrating on them and the lack of motivation. In contrast, only four students made negative comments in 2011. Two of these were about the limited vocabulary range taught for the IELTS, one was about the amount of time spent writing, and one concerned an annoying partner and so was extraneous to class content.

Lastly, this study only partially corroborated instructor impressions gathered during the unstructured interviews after the classroom observation time. Both instructors had indicated that they tended to avoid introducing communicative activities while teaching writing because planning for these sorts of activities was more complicated. Moreover, both instructors felt that too much class time was needed to execute these activities as compared to other sorts of writing preparation tasks. During the second part of this study it became clear that these instructor impressions were only partially true, as will be discussed in Section 5 below.

\section{Discussion}

In this section, the results obtained in the two portions of the study reported above are discussed, and some study limitations for each are reviewed.

The first portion of the study, dedicated to classroom observation of colleagues involved in high-stakes exam preparation, revealed a surprisingly high CLT content 
in the exam preparation class, with just over one third of class time dedicated to activities which could be considered communicative according to Nunan's (1989) list. CLT activities utilized during writing instruction were far fewer, however. Roughly 2.5 hours of observed class time was dedicated to each exam task (reading, writing, listening, speaking), but only 45 minutes of the time spent teaching writing was spent in a communicative task. This compares to nearly 60 minutes of communicative activities dedicated to each of the other exam tasks. Instructors confirmed their reluctance to introduce CLT content during the writing portion of the exam training class because they deemed that these types of activities required more time both to plan and to execute in class.

With these results in mind, for the second part of the study I aimed to include at least four hours of communicative activities during the ten hours of writing task preparation time in class. These activities included jigsaw dictations, peer and group editing, creation of IELTS writing tasks, task comparison and sentence auctioning. Student satisfaction, as measured through a brief end-of-course survey, was very high, with an average of nearly 25/32 students (78\%) reporting satisfaction with their improvement in 2011 as compared to an average of only $20 / 34$ (59\%) in 2009. Negative comments were likewise fewer, with a drop from ten negative comments in 2009 to only four in 2011.

The two exam preparation sessions in 2009 and 2011 referred to in the previous paragraph were similar in cohort size and student type, and both were IELTS training classes. The only identifiable variable between the two is the introduction of a greater number of communicative activities. Student comments corroborate the hypothesis that the CLT method introduced in the 2011 class enhanced student satisfaction. Comments from learners showed that communication was important as students negotiated meaning and form with their classmates. Cooperation among learners was essential to complete activities such as jigsaw dictations or sentence auctioning. Peer and group editing forced them to concentrate on communicating about writing, thus enhancing their metalinguistic grasp of writing and its component parts. Learner comments revealed that vocabulary can be learned collaboratively. In short, the introduction of communicative activities seems to have led students to reflect on their writing, stay more focused and interested, become more autonomous writers and experience less frustration and boredom. Student results on the actual 2011 IELTS tests were very good as well, with no student receiving less than $7.5 / 9$ on the writing section.

Lastly, it is useful to compare these results to Luxia's (2007) study, where the researcher considered whether a standardized exam had a positive washback on the pedagogical practices of English teaching writing in Chinese schools. The researcher does not find any evidence of a positive washback effect, and concludes that high-stakes exams are not likely to be a positive agent for classroom change. This interesting study takes the exact opposite approach to the study reported here; in the present study the instructor sought to change her own pedagogical 
practices in teaching exam writing task preparation, incorporating additional CLT methods in order to have a positive impact on students and their results. The changes undertaken seem to have had the intended results.

As mentioned in the results section above, planning communicative activities for writing proved to be as time consuming as the observed instructors had mentioned. This was most especially true because there were so few ready-made tasks of this type available in exam preparation text books, which places the burden for task preparation entirely on the shoulders of the instructor. Each task had to be planned and materials created for each step of the activity. Although this is disheartening, it need not always be true, since an increase in CLT materials for exam preparation is only a matter of time and market request. A few books with ready-to-use, exam-oriented communicative activities are available, such as Brook-Hart's Instant IELTS (2004), and more would soon follow if the need were felt. Finally, it should be mentioned that although completing communicative activities in class did require a certain amount of time, the time required was no more than that needed for any other sort of writing instruction. Preparing students for the writing portion of high-stakes exams is time consuming whatever approach is used; the CLT approach did not seem any more unwieldy or lengthy in execution than more traditional exam writing classes in the past.

In terms of study limitations, two immediately come to mind. It is clearly almost impossible to divide classroom time into neat segments of separate skills. Thus an activity which aims to teach writing skills, such as a jigsaw dictation, naturally also develops speaking and listening skills, since students in this activity have to speak, listen and write. Likewise for sentence auctioning, students have to speak both to auction and to bid on the sentences they want, and then to speak again in their groups to organize the text into a final, acceptable written form. While not a limitation in terms of content or quality of classroom time or student output, it is a numeric limitation, since clearly the four hours dedicated to communicative tasks while teaching writing involve speaking, listening and reading skill work as well. This is of course likewise true of writing skills which are naturally exercised even while ostensibly working on other skills, such as note taking while listening or writing up summaries after reading.

Another limitation is that the connection between CLT and satisfaction may only be inferred, it cannot be conclusively proven. Although the introduction of CLT activities is the most probable cause of the much greater levels of satisfaction in 2011 as compared to 2009 , the link could only be demonstrated by successfully replicating the study. This is discussed briefly in Section 6 below. 


\section{Conclusion}

The study reported in this paper indicates that CLT practices are not uncommon in exam preparation classes, even while preparing for the writing task. The results also point to the probability that an increase in the quantity of communicative activities while working on exam writing preparation can have a positive effect on student participation and satisfaction, while student results on the highstakes exam can remain quite good. These activities require more time to plan and prepare than other types of exam writing preparation classes, but the time needed to execute the activities in class does not appear to be greater than other types of activities aimed at improving student writing. Moreover, preparation time would decrease if additional communicative materials were readily available on the market.

Future research could usefully concentrate on validating the findings of this preliminary study by comparing the results of comparable cohorts of candidates prepared for the writing section of a high-stakes exam with or without a CLT approach in a single time period. This replication of the research would allow a comparison of results between studies. Two types of survey studies would also be helpful. Firstly, a further survey of the quantity, both in terms of numbers of activities and of time spent in the classroom, of communicative tasks used while preparing the writing task for a high-stakes exam would be a useful complement to the work undertaken here. Secondly, a survey of the types of communicative activities currently in use in preparing students for exam writing papers would be very helpful and a useful step towards building up a repertoire of readily-available tasks, thereby decreasing the amount of time needed to prepare communicative tasks for this purpose.

\section{Acknowledgements}

I would like to thank my colleagues at the University of Siena who allowed me to observe their classes, as well as my students at the Scuola Normale Superiore who participated in this study by completing the surveys.

\section{References}

Brook-Hart, G. 2004. Instant IELTS: Ready-to-use tasks and activities. Cambridge: CUP.

Charge, N., Taylor L.B. 1997. Recent developments in IELTS. ELT Journal 51: 374-380.

Harmer, J. 2004. How to Teach Writing. Harlow: Pearson Education.

Hyland, K. 2002. Teaching and Researching Writing. Harlow: Pearson Education.

Kim, J. 2010. Effective communicative language teaching in a test-preparation class: Is it possible? Hawaii Pacific University TESOL Working Paper Series 8: 39-43. 
Luxia, Q. 2007. Is testing an efficient agent for pedagogical change? Examining the intended washback of the writing task in a high-stakes English test in China. Assessment in Education: Principles, Policy \& Practice 14: 51-74.

Nunan, D. 1989. Designing Tasks for the Communicative Classroom. Cambridge: CUP.

Richards, J.C., Rodgers T.S. 2001. Approaches and Methods in Language Teaching. Cambridge: CUP.

Savignon, S.J. 2002. Communicative curriculum design for the $21^{\text {st }}$ century. English Teaching Forum 40: 2-7. 


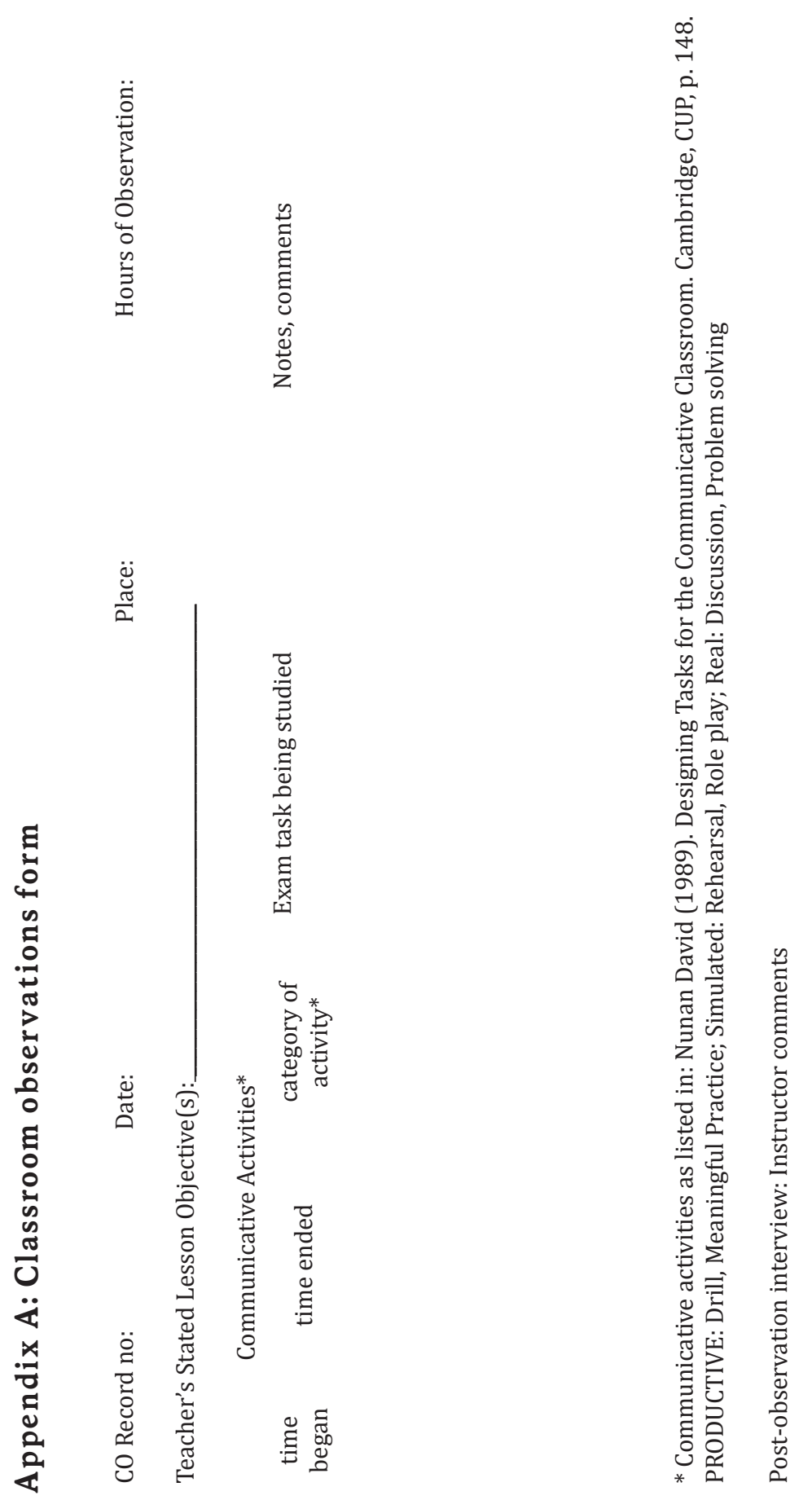




\section{Appendix B: Student post-instruction survey}

Please take a moment to complete the following survey concerning the IELTSpreparation course you just completed.

As explained, all responses are anonymous and will have no influence on your course results.

Please give as much information as you wish to the "why" portions of the questions. THANK YOU!

As a result of this course

1. Has your writing improved? Why?

2. Do you think you control your writing more easily? Why?

3. Has your vocabulary knowledge improved?Why? 